\title{
Processing of Used Beveraged Waste for Production of Hydroge Gas with Electrolysis Process Using NaOH Catalyst
}

\author{
Widayat $^{1,2^{*}}$, Mochammad Faiq Yumna ${ }^{1}$, Muhammad Hilmazar $^{1}$, Hantoro satriadi and Aji \\ Prasetyaningrum \\ ${ }^{1}$ Department of Chemical Engineering Diponegoro University, JL. Prof. Soedarto, SH, 50239 \\ Semarang, Indonesia \\ ${ }^{2}$ Advanced Material Laboratory Central Laboratory for Research and Service Unit Diponegoro \\ University, JL. Prof. Soedarto, SH, 50239 Semarang, Indonesia
}

\begin{abstract}
The production of hydrogen gas as an alternative fuel cell which is a renewable energy, is now in great demand by utilizing waste aluminum beverage cans and added water using $\mathrm{NaOH}$ catalyst by electrolysis process. The research method will be carried out by inserting 1 gram of aluminum pieces into a tube and $300 \mathrm{ml}$ of distilled water followed by a $\mathrm{NaOH}$ catalyst. Both faucets are opened to release air during the filling process. The faucet is closed when the height of the solution in both tubes is the same. Then turn on the DC flow, then adjust the voltage according to the variable. The filling period is recorded until the specified reaction time. The results of the gas volume obtained are recorded, and the hydrogen obtained is determined by the flame test. From the research it can be concluded that the hydrogen gas produced from the reaction can be identified by means of a flame test. The characteristics of hydrogen gas appear in flames which tend to disappear in the air. At Al 5 gr Weight : 5 $\mathrm{M} \mathrm{NaOH}$ concentration is the largest volume of hydrogen. The reaction time of 150 minutes will produce a lot of hydrogen gas. The largest volume of hydrogen gas lies at a voltage of 20 volts.
\end{abstract}

\section{Introduction}

Used cans are one example of solid waste that can be recycled. The rate of recycling aluminum cans is higher than other used packaging materials because of the high value of scrap metals and is accompanied by more highly advanced technology for sorting and recovering. Recycling of aluminum beverage can is a profitable and successful industry, most industrial countries have national can recycling associations that connect can collectors with buyers, but still differ from country to country depending on existing collection, sorting and recycling schemes and its development [1]. Aluminum is a metal that is lightweight and durable, silver when cut, good conductor of heat and electricity, and easily formed by molding and extrusion. Aluminum also has excellent thermal properties

* Corresponding author: widayat@live.undip.ac.id 
and corrosion resistance has its use in air conditioning, cooling and heat exchange systems [2]. Utilization of aluminum waste from used beverage cans to produce hydrogen gas. Production of hydrogen gas that utilizes waste in the surrounding environment is also energy that is easily converted into electricity and fuel is safe for the environment, because it does not leave toxic and clean waste, only water and chemicals such as aluminum hydroxide $\mathrm{Al}\left(\mathrm{OH}_{3}\right)$ can be reused [3].

Hydrogen production can also be done by steam reforming of hydrocarbons [4,5]. The electrolysis process is one of the technological processes to produce hydrogen gas that is eco-friendly compared to other processes. Electrolysis systems that have developed are alkaline water electrolysis (AWE), proton exchange membranes (PEMs), alkaline anion exchange membranes (AEMs), and solid oxide water electrolysis (SOE) [6]. In addition, hydrogen can be produced from the reaction of metals and water with the help of a catalyst. One of them is hydrogen produced from aluminum metal which is reacted with water using a $\mathrm{NaOH}$ catalyst [7]. Besides that, the electrolysis of water can also be used to produce hydrogen. Electrolysis of water is an event of the decomposition of water compounds $\left(\mathrm{H}_{2} \mathrm{O}\right)$ to oxygen $\left(\mathrm{O}_{2}\right)$ and hydrogen gas $\left(\mathrm{H}_{2}\right)$ which is connected to an electric current through water as an electrolyte. At the cathode, two water molecules react by capturing two electrons, reduced to $\mathrm{H}_{2}$ gas and hydroxide ions $(\mathrm{OH})$. Meanwhile at the anode, two other water molecules break down into oxygen gas $\left(\mathrm{O}_{2}\right)$, releasing $4 \mathrm{H}^{+}$ions and flowing electrons to the cathode. $\mathrm{H}^{+}$and $\mathrm{OH}$ ions are neutralized to form several water molecules. Factors that influence electrolysis of water include: temperature, pressure, and quality of electrolytes [8]. Hydrogen gas produced from the water electrolysis process can be reviewed from thermodynamic reviews and catalyst reviews. According to the thermodynamic review, if the electrolysis temperature used is higher, it will affect the reduced electrical energy needed. This can be explained by the thermodynamic characteristics of water molecules that the reaction of molecular separation increases when the temperature increases [9]. While from the catalyst review, that the use of basic catalysts can cause an increase in hydrogen gas [10]. A catalyst is a substance that can accelerate the rate of chemical reactions at a certain temperature, without undergoing changes or being used by the reaction itself and provides a preferred pathway with lower activation energy [11]. Some previous studies, processing used beverage cans into hydrogen gas using catalysts such as sodium hydroxide $(\mathrm{NaOH})$. Where $\mathrm{NaOH}$ is a strong base. Research conducted by Porciuncula et al. (2012), using $\mathrm{KOH}$ and $\mathrm{NaOH}$ catalysts, the reaction temperature was between 295 and $345 \mathrm{~K}$, the thickness of the aluminum used was 0.02 ; 0.5; and $1 \mathrm{~mm}$ and the concentration of $\mathrm{KOH}$ and $\mathrm{NaOH}$ is $2 ; 2.5$; and $3 \mathrm{~mol}$. $\mathrm{L}^{-1}$ get the result that the $\mathrm{NaOH}$ catalyst reacts faster and the hydrogen yield is greater than the $\mathrm{KOH}$ catalyst [12].

\section{Materials and Methods}

\subsection{Sample Preparation}

Used beverage cans obtained from scavengers in Meteseh, Semarang, are washed thoroughly with soap and water. Then a few used beverage cans were sanded with paint. Then the used beverage cans are cut into small pieces with a size of $0.5 \mathrm{~cm}$ x $0.5 \mathrm{~cm}$ by a certain gram. 


\subsection{Production of Hydrogen Gas with Voltameter Hofmann}

Pieces of used beverage can of variable weight were put into tubes and $300 \mathrm{ml}$ of distilled water followed by $\mathrm{NaOH}$ catalyst. During the filling process the two taps are opened to release air. The faucet is closed when the height of the solution in both tubes is the same. Turn on the DC flow, then adjust the voltage according to the variable. The filling period is recorded until the specified reaction time. Record the results of the volume of gas obtained, the hydrogen obtained is determined by the flame test. Data collection is repeated for other variables.

\subsection{Analysis of Results}

The volume of hydrogen recorded in the measuring instrument is still recorded in units of $\mathrm{ml}$, therefore it must be converted to $\mathrm{ml} / \mathrm{x}$ gr Al. Where is the formula to change as follows:

$$
\text { Hydrogen Volume }=\frac{\text { Resulting volume size }(\mathrm{ml})}{\text { mass of } \mathrm{Al}(\mathrm{gr} \mathrm{Al})}
$$

\section{Results and Discussion}

\subsection{Qualitative Hydrogen Test with a Fire}

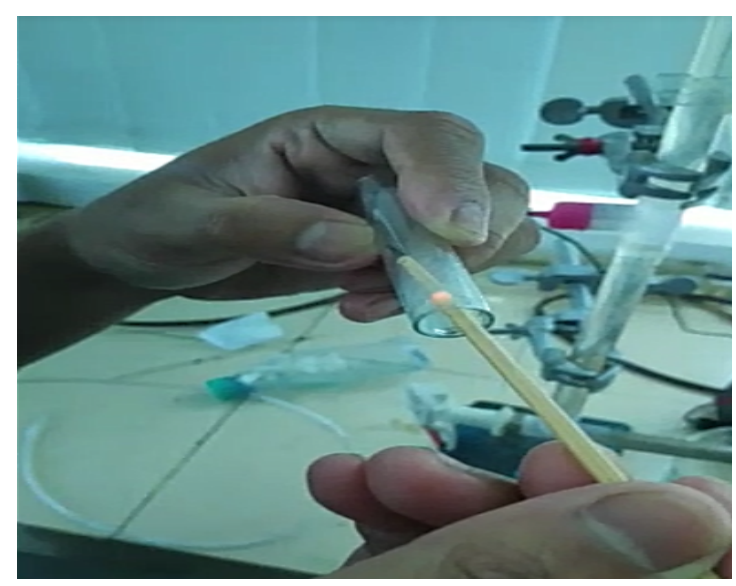

Fig. 1. Hydrogen Test with Fire

From the experiments that have been carried out in a device similar to the Hofmann voltammeter, with the reaction:

$$
2 \mathrm{Al}(\mathrm{s})+2 \mathrm{NaOH}(\mathrm{aq})+2 \mathrm{H} 2 \mathrm{O}(\mathrm{l}) \rightarrow 2 \mathrm{KAlO} 2(\mathrm{aq})+3 \mathrm{H} 2(\mathrm{~g})
$$

The above experiment was carried out with a composition ratio between the weight of $\mathrm{Al}$ and $\mathrm{NaOH}$ catalyst concentration was $1 \mathrm{gr}$ : $1 \mathrm{M}$. As for the electrode voltage is 12 volts, with the reaction time is 60 minutes. Hydrogen testing is done by a flame test. Hydrogen produced from the reaction process for 60 minutes, then opened the top valve cap in order to drain hydrogen gas into a small tube. Then prepare the sticks skewers and matches as a fire to put into a small tube enclosure filled with hydrogen gas. 
From the experimental results obtained hydrogen gas, proven by a flame. The flame test was identified when a skewer ignited with fire was inserted into a small tube enclosure, showing a small flame. Based on these results, it proves that hydrogen gas is very flammable and will burn in free air. In addition, hydrogen gas has the characteristic of a flame that tends to disappear quickly in the air, so that the damage caused by the explosion of hydrogen gas is lighter than the hydrocarbon explosion [13].

\subsection{Hydrogen Comparative Control of Catalyst Effects}

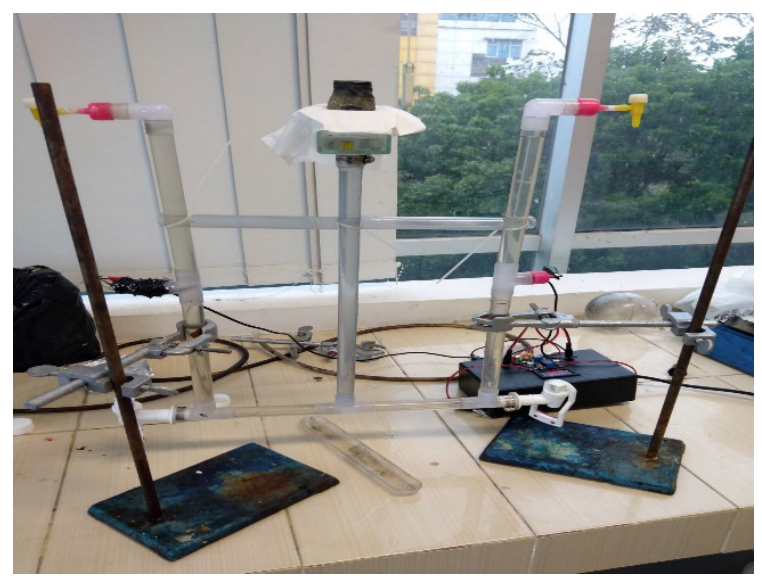

Fig. 2. First Experiment: Hydrogen Electrode + Aluminum + Catalyst

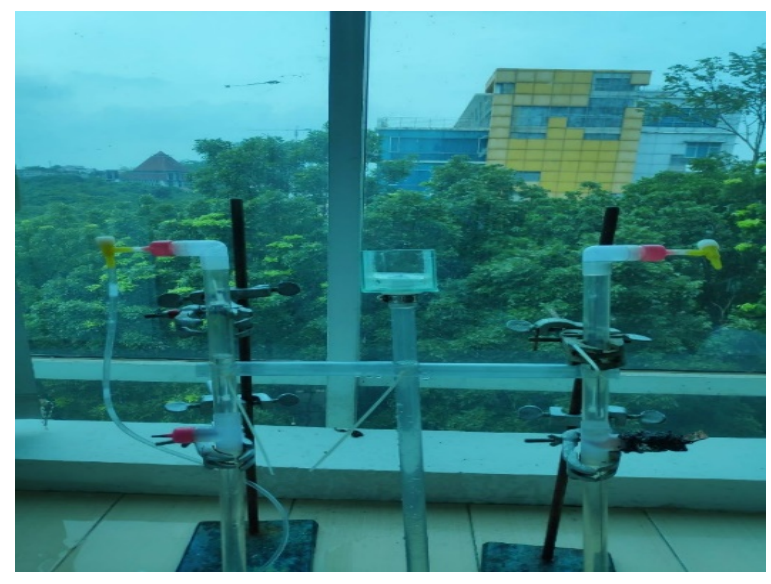

Fig. 3. Second Experiment: Hydrogen Electrode + Aluminum $+\mathrm{H}_{2} \mathrm{O}$

The comparison test above was carried out as a control for hydrogen testing with or without a catalyst. Experiment 1 was carried out using electrodes that had an aluminum reaction and a $\mathrm{NaOH}$ catalyst. Experiment 2 was carried out using electrodes, but the difference between experiment 1 was that the reaction was only aluminum and water. In experiment 1 with aluminum weight of 1 gram, concentration of $1 \mathrm{M}$, reaction time of 1 hour, and a voltage of $12 \mathrm{~V}$. As for experiment 2 with aluminum weight of 1 gram, water with a volume of $300 \mathrm{ml}$, and a voltage of $12 \mathrm{~V}$. 
From the experimental results obtained in experiment 1 produced hydrogen of $3.5 \mathrm{ml} /$ $1 \mathrm{gr} \mathrm{Al}$. Whereas in experiment 2 it was found that hydrogen was $1.0 \mathrm{ml} / 1 \mathrm{gr} \mathrm{Al}$. When viewed from the production of hydrogen produced between experiments 1 and 2 , the use of sodium hydroxide $(\mathrm{NaOH})$ is a catalyst that acts to accelerate the reaction with aluminum .

Experiment 2 without using a $\mathrm{NaOH}$ catalyst can still produce hydrogen, but the quantity of hydrogen produced is still large in Experiment 1. As for Experiment 2 the reaction is as follows:

$$
2 \mathrm{Al}+6 \mathrm{H}_{2} \mathrm{O} \rightarrow 2 \mathrm{Al}(\mathrm{OH})_{3}+3 \mathrm{H}_{2}
$$

The reaction between aluminum and water if reacted will produce hydrogen gas. The existence of a catalyst that concentrates on Experiment 1, can affect the speed of aluminum waste that reacts to produce hydrogen. The greater the concentration used, the faster the time needed for hydrogen gas production, so that it will affect the quantity of hydrogen produced [14].

\subsection{Comparison of Addition of $\mathrm{NaOH}$ Catalyst Concentration and Aluminum Weight to Volume of Hydrogen Gas Produced}

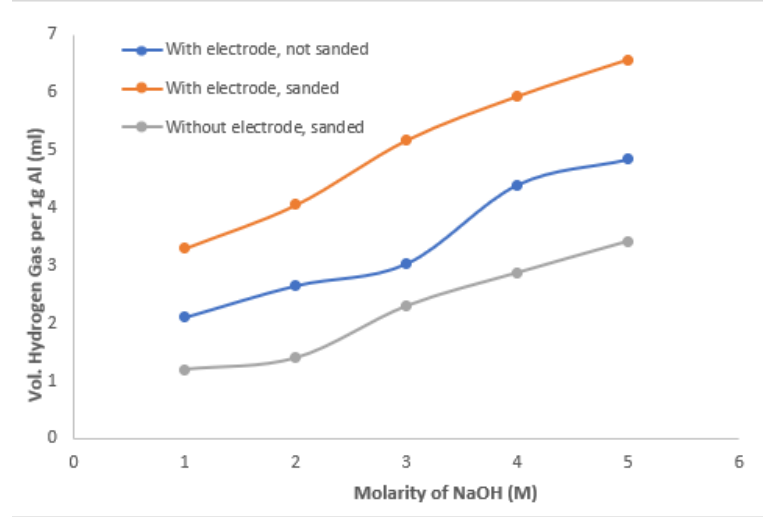

Fig. 4. Comparison of $\mathrm{Al}$ Weight \& $\mathrm{NaOH}$ Catalyst Concentration to $\mathrm{H} 2$ gas volume produced

The graph above shows the relationship between the concentration of $\mathrm{NaOH}$ catalyst and the weight of aluminum used in the experiment with the volume of hydrogen gas produced per 1 gram of $\mathrm{Al}$ sample. The comparison of the increase in $\mathrm{NaOH}$ concentration in the experiment was also followed by the increase in the weight of the Al sample, at the 1 $\mathrm{M} \mathrm{NaOH}$ concentration: the weight of the $\mathrm{Al} 1 \mathrm{gr}$ sample and so on until the $5 \mathrm{M} \mathrm{NaOH}$ concentration: the weight of the Al 5 gram sample. Experiments carried out with the same voltage that is 12 volts and the same experiment time for 1 hour. It can be seen on the graph that the experiments were carried out under 3 different conditions, namely using electrodes with Al samples not sanded, using electrodes with Al samples in sandpaper, and without using electrodes with Al samples on sandpaper.

In the graph above, it can be seen that the addition of $\mathrm{NaOH}$ catalyst causes an increase in the amount of hydrogen gas produced. It can also be seen from the three experiments that have been carried out, experiments with electrodes and $\mathrm{Al}$ samples in sandpaper produce a greater volume of hydrogen gas compared to experiments using electrodes and Al samples not sanded, and experiments without electrodes and Al samples on sandpaper. The purpose 
of sanding on the $\mathrm{Al}$ sample is to remove the paint from the used beverage cans, so that the $\mathrm{Al}$ content in the sample is not obstructed by paint and $\mathrm{Al}$ can react perfectly so as to produce more hydrogen gas.

Our results show that the greater the concentration of $\mathrm{NaOH}$ used, the greater the volume of hydrogen gas produced, this can occur due to the function of the $\mathrm{NaOH}$ catalyst which has the role of accelerating the reaction to form hydrogen gas. Although the time used is equal to 1 hour, this is also influenced by the amount of aluminum used, where when the amount of aluminum reacted increases with the addition of the $\mathrm{NaOH}$ catalyst, the hydrogen gas produced will be more and more. This happens due to changes in bilox in aluminum and hydrogen. When $\mathrm{Al}$ forms $\mathrm{Al}(\mathrm{OH}) 4-$, the $\mathrm{Al}$ oxidation state changes from 0 to +3 , while the oxidation state $\mathrm{H}$ from +1 to 0 . So that the redox reaction that occurs as a result of the $\mathrm{Al}$ element that has amphoteric properties undergoes the same bilox changes under conditions acid or base. As a comparison, the results of research conducted by Kumar and Surendra (2013) state that the $\mathrm{NaOH}$ solution reacts with $\mathrm{Al}$ to bind $\mathrm{OH}$ - from $\mathrm{H} 2 \mathrm{O}$, then form $\mathrm{NaAl}(\mathrm{OH}) 4$ and $\mathrm{H} 2$ gas [15]. In addition, the amount of raw material used can also affect the volume of hydrogen gas produced.

Our results also show that experiments using electrodes produce more hydrogen gas than those without using electrodes. This happens because when using an electrode at a certain voltage, it can help break down water molecules into oxygen and hydrogen, so the process of forming hydrogen becomes more optimal. Electrolysis plays an active role in redox reactions by accumulating or consuming electrode material used. As a comparison, the research conducted by Yuvaraj and Santhanaraj (2014), that hydrogen production increases gradually with increasing electrolytic concentration. This can occur because the amount of current passing depends on the ability to deliver electricity from the electrodes and electrolyte concentration. In another perspective, the increase in hydrogen gas with increasing electrolyte concentrations is due to the greater number of effective ion collisions per unit time.

\subsection{Correlation of Reaction Time to the Volume of Hydrogen Gas Produced}

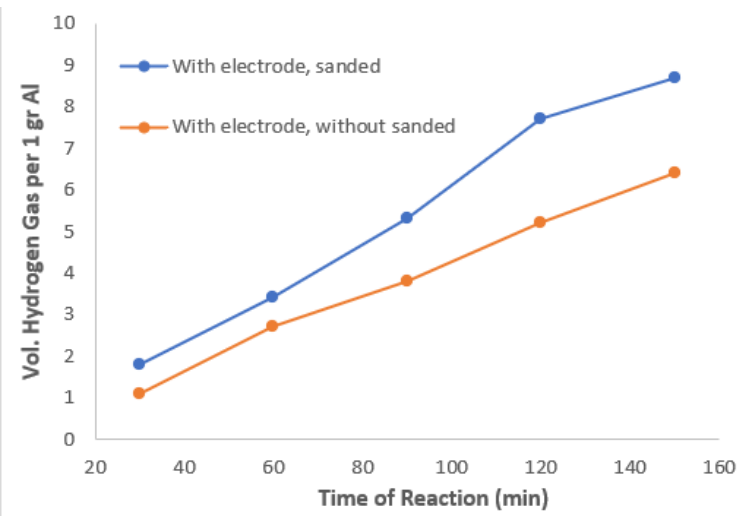

Fig. 5. Correlation of Reaction Time to the Volume of Hydrogen Gas Produced

The graph above shows the relationship between the length of reaction time carried out on the volume of hydrogen gas produced. The reaction time test is carried out at 30,60, 90, 120,150 minutes. The experiment was carried out with a $1 \mathrm{M} \mathrm{NaOH}$ catalyst concentration, a voltage of 12 Volts, an aluminum sample weight of 1 gram, and an experiment was carried out using electrodes with Al samples sanded and not sanded. 
In the graph above it can be seen that the longer the time of the experiment, the more hydrogen gas is produced. It can also be seen the difference between experiments using samples of $\mathrm{Al}$ sanded and not sanded. The purpose of sanding on the Al sample is to remove the paint from the used beverage cans, so that the $\mathrm{Al}$ content in the sample is not obstructed by paint and $\mathrm{Al}$ can react perfectly so as to produce more hydrogen gas.

The research we have done shows that the longer the reaction time, the more hydrogen gas is obtained. In this case, the difference is shown in the thickness of the aluminum contained in the two different samples, namely in the sample that has been sanded, the hydrogen content is greater than the sample that is not sanded, due to the presence of sticking paint covering the aluminum and reducing the thickness than the Al sample. For comparison, the study conducted by Porciuncula et al. (2012), where at the same concentration of $\mathrm{NaOH}$ but at different thicknesses of aluminum $(0.5 \mathrm{~mm}$ and $1 \mathrm{~mm})$, the volume of hydrogen gas produced from aluminum $1 \mathrm{~mm}$ is greater than that of aluminum with a thickness of $0.5 \mathrm{~mm}$. It was also mentioned that hydrogen production is influenced by three things namely temperature, base catalyst concentration, and the shape of the metal. Thus, it can be concluded that even though the reaction times carried out in the same experiment, thicker $\mathrm{Al}$ samples can produce more hydrogen gas as well.

\subsection{Correlation of Voltage Differences to the Volume of Hydrogen Gas Produced}

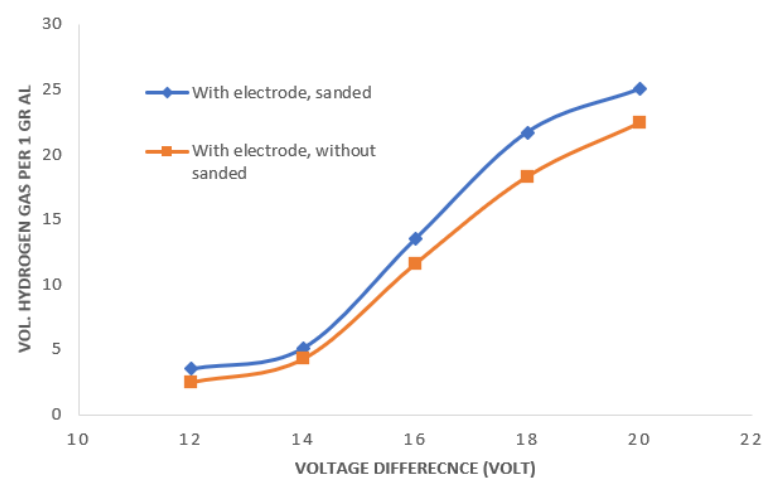

Fig. 6. Correlation of Voltage Differences to the Volume of Hydrogen Gas Produced

The graph above shows the relationship of the voltage difference used in each experiment to the volume of hydrogen gas produced. The magnitude of the voltage difference used in the experiment is $12,14,16,18$, and 20 Volts. The experiments were carried out using electrodes, the $\mathrm{NaOH}$ catalyst concentration was $1 \mathrm{M}$, the reaction time was 1 hour, and the weight of the $\mathrm{Al}$ sample was 1 gram under the condition of the sample being sanded and not sanded.

From the graph above it can be seen that the increase in voltage causes an increase in the hydrogen gas produced. It can also be seen in the process that uses sandpaper Al that is sandpaper to produce hydrogen gas which is higher than that which is not sanded. The purpose of sanding on the Al sample is to remove the paint from the used beverage cans, so that the Al content in the sample is not obstructed by paint and $\mathrm{Al}$ can react perfectly so as to produce more hydrogen gas.

Theoretically, the electrochemical reaction process has the legal basis of Faraday's 2nd law as follows:

Where

$$
\mathrm{W}=\mathrm{E} \times \mathrm{I} \times \mathrm{t}
$$

- W = Mass

- E = Valence

- I = Current 
$-\mathrm{t}=$ Time

If Faraday's second law is related to the research we have done, the greater the voltage used for the electrolysis process will produce hydrogen gas with a large mass as well. Our results show that the higher the electric voltage used, the greater the volume of hydrogen gas produced. This is because the high voltage difference to excite electrons to produce $\mathrm{H}+$ radicals is also higher. As a comparison, research conducted by Yuvaraj and Santhanaraj (2014), states that the effect of the applied voltage on hydrogen production using cylindrical graphite electrodes at a temperature of $593 \mathrm{~K}$ with a concentration of $\mathrm{KOH} 0.025 \mathrm{M}$, and voltages varying from 4.5 to $12 \mathrm{~V}$ indicate that the rate of hydrogen gas production gradually increases with the increase in voltage applied on the grounds that there is a uniform increase in charge density on the surface of the cylindrical electrodes [17].

\section{References}

1. Bdeir, Layla M. H., and AlSaffar, Kiffaya A, Recycling of Aluminum Beverage Cans. Journal of Engineering and Development 12(3) pp.157-163 (2008)

2. Gandara, M. J. Freiria. Aluminum : The Metal of Choice. Materials and Technology (3) 261-265 (2013)

3. Zikri, A., Erlinawati, Trisnaliani, L., and Wulandari, D, The Design of ACE (Aluminum Corrosion and Electrolysis) Reactor and Its Performance to Produce Hydrogen from Beverage Cans. Reaktor, 17(4): 210-214 (2017)

4. Widayat, Hartono, R, Elizabeth,E., and Annisa, A.N, Study of Catalyst Variation Effect in Glycerol Conversion Process to Hydrogen Gas by Steam Reforming. IOP Conference Series: Materials Science and Engineering 349 (2018)

5. Munfarida, S., Widayat, Satriadi, H., Cahyono, B., Hadiyanto, Philia, J., Prameswari, J., Geothermal industry waste-derived catalyst for enhanced biohydrogen production. Chemosphere, 258 (2020)

6. Widarningtyas, R. P., Sulistyo, Widayat. Potential of Hydrogen Production Through Electrolysis Using Solar Radiation Around Semarang. E3S Web of Conferences 125 (2019)

7. Soler, L., Macanas, J., Munoz, M., and Casado, J, Aluminum and Aluminum Alloys as Sources of Hydrogen for Fuel Cell Applications. Journal of Power Sources 169, 144149 (2007)

8. Rashid, M. Md, Hydrogen Production by Water Electrolysis: A Review of Alkaline Water Electrolysis, PEM Water Electrolysis and High Temperature Water Electrolysis. International Journal of Engineering and Advanced Technology (IJEAT) 4(3): 80-93 (. 2015)

9. Buelvas, W.L, Temperature as a Factor Determining on Water Electrolysis. International Journal of Engineering Trends and Technology (IJETT) 7(1):5-9 (2014)

10. S. Kadarwati, and S. Wahyuni, Characterization and Performance Test of Palm Oil Based Bio-Fuel Produced Via Ni/Zeolite-Catalyzed Cracking Process, International Journal of Renewable Energy Development, vol. 4, no. 1, pp. 32-38, (2015)

11. Sikander, Umair, Effects of catalytic bed position on hydrogen production by methane decomposition. Journal of Mechanical Engineering and Sciences 12(1): 3313-3320 ( 2018)

12. Porciuncula, C. B., Marcilio, N. R., Tessaro, I. C., and Gerchmann, M, Production of Hydrogen In The Reaction Between Alumunium and Water In The Presence of NaOH and $\mathrm{KOH}$. Brazilian Journal of Chemical Engineering 29(2), pp. $337-348$ (. 2012) 
13. Lanz, Andre, Hydrogen Fuel Cell Engines and Related Technologies. College of the Desert, Palm Desert, CA, USA (2001)

14. Buddhi, D, An Experimental Study On The Effect Of Electrolytic Concentration On The Rate Of Hydrogen Production. International Journal of Green Energy, 3: 381-395 (2006)

15. Kumar, S. and Surendra, K. S, Role of Sodium Hydroxide for Hydrogen Gas Production and Storage. Materials and Processes for Energy: Communicating Current Research and Technological Developments, pp.452-463. FORMATEX: (2013)

16. Ujile, A. A., Dirinna, A., and Konne, J, Evaluating the Thermodynamics and Kinetics of Production of Caustic Soda from Brine. Journal of Modern Physics, 2018, 9, pp. 99111 (2018)

17. Yuvaraj, A. L., and Santhanaraj, D, A Systematic Study on Electrolytic Production of Hydrogen Gas by Using Graphite as Electrode. Materials Research 17(1): 83-87 ( 2014) 